\title{
Towards the development of a Cavendish banana resistant to race 4 of fusarium wilt: gamma irradiation of micropropagated Dwarf Parfitt (Musa spp., AAA group, Cavendish subgroup)
}

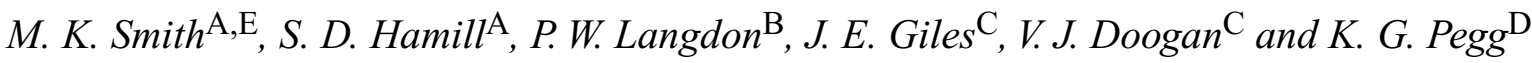 \\ ${ }^{A}$ Department of Primary Industries and Fisheries Queensland, Maroochy Research Station, \\ PO Box 5083, SCMC, Nambour, Qld 4560, Australia. \\ ${ }^{B}$ Department of Primary Industries and Fisheries Queensland, South Johnstone Research Station, \\ PO Box 20, South Johnstone, Qld 4859, Australia. \\ ${ }^{C}$ Department of Primary Industries and Fisheries Queensland, \\ Locked Mail Bag 4, Yeerongpilly, Qld 4105, Australia. \\ DDepartment of Primary Industries and Fisheries Queensland, \\ 80 Meiers Road, Indooroopilly, Qld 4068, Australia. \\ ECorresponding author. Email: mike.smith@dpi.qld.gov.au
}

\begin{abstract}
Dwarf Parfitt', an extra-dwarf Cavendish cultivar with resistance to subtropical race 4 Fusarium oxysporum f. sp. cubense (Foc), was gamma irradiated at a dose of $20 \mathrm{~Gy}$ and putative mutants were recovered with improved agronomic characteristics. Further screening of putative mutants for improved yield and fruit size, as well as a degree of resistance to fusarium wilt, led to the selection of a line (DPM25) with improved productivity when grown on soils infested with subtropical race 4 Foc. DPM25 was equal to the industry standard, 'Williams', in every agronomic trait measured and it consistently showed a lower incidence of fusarium wilt. Further improvement of field resistance to race 4 Foc is needed in DPM25 and further cycles of mutation induction and selection is an option discussed.
\end{abstract}

Additional keywords: mutation breeding, somaclonal variation, tissue culture.

\section{Introduction}

The Australian banana industry, and indeed the world export trade, is based on the Cavendish (Musa spp. AAA group) subgroup of dessert bananas. Although highly productive in a range of environments, Cavendish is susceptible to a particularly devastating race of Fusarium oxysporum f. sp. cubense ( $F o c$ ), race 4. Because of the persistent nature of $F O C$ in soils and the lack of effective chemical control strategies, the development of race 4 Foc resistant cultivars has been a priority in genetic improvement programs for the past 20 years (Moore et al. 2001).

Conventional breeding strategies have not delivered a Cavendish cultivar resistant to Foc or a suitable replacement largely due to the extreme sterility encountered in this subgroup of bananas. The Cavendish subgroup is composed of triploid (AAA) cultivars that are totally seedless (Robinson 1996). Attention is being given to biotechnology approaches to improve Cavendish cultivars, including genetic transformation (Becker et al. 2000), but currently in vitro mutation breeding programs have delivered the most promising results (Smith et al. 2005).

The Taiwan Banana Research Institute established a Cavendish breeding program in 1985 based on field screening somaclonal variants for resistance to race $4 \mathrm{Foc}$ following mass in vitro propagation. The program has produced 12 resistant clones; however, a good substitute for 'Giant Cavendish' has not yet been obtained (Hwang 2001). Whereas some resistant clones carry inferior agronomic characters, others have fruit quality defects. Nevertheless a race 4 Foc resistant clone, 'Tai Chiao No. 1', was released for commercial planting in 1992 and shows significantly lower incidence of fusarium wilt when planted in race $4 \mathrm{Foc}$ infested soils $(5.1 \%-6.5 \%)$ compared with the susceptible Giant Cavendish (42.6\%-69.0\%) (Hwang 2001). Further cycles of in vitro propagation and selection of somaclonal variants with improved agronomic characters while retaining race 4 Foc resistance have continued with Tai Chiao No. 1 (Tang and Hwang 1998). Recently a new resistant clone superior to the agronomic characters and productivity of Tai Chiao No. 1 has been obtained (Hwang 2001). Other in vitro mutation breeding programs based on either somaclonal variation (de Beer et al. 2001) or gamma irradiation (Smith et al. 1994) have produced more resistant clones but have deleteriously altered the agronomic characters of the original Cavendish cultivar. The work reported in this present paper has taken a different strategy. Instead of starting with a 
commercial Cavendish cultivar susceptible to race 4 Foc and attempting to increase its resistance, an extra-dwarf Cavendish cultivar called 'Dwarf Parfitt' resistant to race 4 Foc (Pegg et al. 1996) was irradiated and putative mutants were screened for improved agronomic features while attempting to retain field resistance to race 4 Foc.

\section{Materials and methods}

Plant materials and establishment of micropropagated bananas Conditions for the initiation and growth of micropropagated bananas have been described previously (Hamill et al. 1992). Briefly, Williams and Dwarf Parfitt were initiated on a Murashige and Skoog (1962) basal medium supplemented with $10 \mu \mathrm{mol} / \mathrm{L}$ benzylaminopurine, $2 \%$ sucrose and $0.8 \%$ Difco-Bacto agar. This medium also supported rapid shoot multiplication. Cultures were incubated at $28^{\circ} \mathrm{C}$ with a $16: 8 \mathrm{~h}$ light: dark photoperiod. Cool white fluorescent tubes provided a photon flux density at the culture surface of about $80 \mu \mathrm{mol}$ quanta $/ \mathrm{m}^{2}$.s. Before acclimatisation in the glasshouse, plants were subcultured to a hormone-free medium for root initiation and the development of vigorous, single shoots. Plants were established in the field when they reached a height of $20 \mathrm{~cm}$ in 2.5 -L planter bags.

\section{Mutation induction}

The irradiation procedure described by Smith et al. (1994) was originally developed for Williams and involved the transfer of explants, containing the shoot tip and ensheathing leaf bases obtained from micropropagated plants, to Petri dishes that contained a multiplication medium. Cultures were incubated for 7 days before exposure to gamma radiation from a ${ }^{60} \mathrm{Co}$ source. The doses used were $0,10,20,30,40$ and 50 Gy. Dosage was calculated using Fricke dosimetry (O’Donnell and Sangster 1970). Plants were subcultured for 2 or 3 cycles on a multiplication medium before root initiation and acclimatisation in the glasshouse.

\section{Establishment and maintenance of field trials}

The experimental site has been described previously (Smith et al. 1998) and formed part of a commercial Cavendish plantation at Wamuran in subtropical Queensland $\left(27^{\circ} \mathrm{S}, 153^{\circ} \mathrm{E}\right)$ that was abandoned because of losses to fusarium wilt caused by subtropical race 4 Foc. The soil is classified as a yellow ferrosol (gleyed podzolic soil) and is a heavy clay-clay loam of $\mathrm{pH}$ 5.5-6.0. The site was uniformly infested with 3 subtropical race 4 vegetative compatibility groups (VCGs): 0120, 0129 and 01211 (Pegg et al. 1996). A series of field trials were carried out over an extended period, commencing in November 1991 and concluding in April 2003 (Table 1). Some were designed to assess the putative mutants' response to race 4 Foc whereas others also included measurements of yield, productivity and fruit size. The field trial planted in November 1995 from micropropagated plants was in an area unaffected by fusarium wilt. All other trials were at race $4 \mathrm{Foc}$ infested sites as described above. Planting material was either micropropagated plants or 'bits', which are sections of the rhizome containing a well developed growing point and pared to an average weight of 700-800 g. Plants were established at a density of 1600 plants/ha with a spacing of 2.5 by $2.5 \mathrm{~m}$ and grown using standard commercial practices (Gall and Vock 1994).

\section{Measurements}

Blocks were visited weekly and when banana plants started bunching, the pseudostem height (from the soil surface to the point of intersection of the 2 upper-most leaves) and pseudostem circumference (at $30 \mathrm{~cm}$ above ground) were measured, the number of green leaves was counted and the date of bunch emergence recorded. At harvest the following parameters were recorded: date, number of green leaves, total leaf area [calculated using the formula of Robinson and Nel (1985); (leaf length $\times$ maximum leaf width) $\times 0.83$ (conversion factor), bunch weight, bunch stalk weight, number of hands, number of fingers in bunch, number of fingers in the third proximal hand and the length of the middle finger of the outer whorl of the third proximal hand. Agronomic traits were not recorded from plants showing obvious symptoms of fusarium wilt.

\section{Assessment of fusarium wilt infection}

External symptoms of fusarium wilt were recorded at the final, destructive harvest when internal symptoms were also recorded. Plants were judged to have external symptoms of disease if they displayed any sign of wilting, yellowing of foliage, petiole buckling or splitting of the pseudostem base. Severity ratings were on a scale of 1-3 that was developed by the International Network for the Improvement of Banana and Plantain (Jones 1994): 1, no symptoms; 2, mild symptoms; and 3 , severe symptoms. Internal symptoms were recorded from plants that were removed from the soil and cut transversely through the rhizome about one-quarter of the way above the rhizome's base. The cut surface of the rhizome was rated for discolouration on a scale of 1-6 (Jones 1994): 1, no vascular discolouration; 2 , isolated points of vascular discolouration; 3 , less than one-third of the vascular tissue discoloured; 4 , one- to two-thirds of the vascular tissue discoloured; 5 , greater than two-thirds of the vascular tissue discoloured; and 6, total vascular discolouration or discolouration of leaf bases or both.

Experimental design and statistical analysis

Each trial used a completely randomised design and had unequal replication for each mutant line and cultivar due to differences in availability of planting material. For the yield data from the field trials planted in November 1991 and 1995, mutant lines were compared using analysis of variance; whereas, for the field trial planted in October 1998, line comparisons were made using residual maximum likelihood with lines as a fixed effect (tested using the Wald statistic), and rows and columns as random effects. For these trials, the protected LSD test was used to compare treatment means using the significance level of $P=0.05$. Severity of race $4 F O c$ infection was analysed using the Kruskal-Wallis test. Incidence of fusarium wilt was compared using generalized linear models for a binomial distribution with logit link followed, where significant, by pairwise $t$-tests. Again testing was at $P=0.05$.

Table 1. Outline of experiments conducted to assess performance of irradiated Dwarf Parfitt mutant lines

\begin{tabular}{lcccl}
\hline Planting material & Planting date & Completion date & No. of lines & \multicolumn{1}{c}{ Assessment } \\
\hline Bits $^{\mathrm{A}}$ & Nov. 1991 & Nov. 1993 & 22 & Plant crop data; Foc ${ }^{\mathrm{B}}$ \\
Micropropagated & Nov. 1992 & June 1993 & 22 & Foc \\
Micropropagated & Nov. 1992 & Oct. 1993 & 22 & Foc \\
Micropropagated & Nov. 1995 & Oct. 1998 & 7 & Plant and ratoon crop data \\
Micropropagated & Nov. 1996 & Oct. 1997 & 7 & Foc \\
Bits & Oct. 1998 & Apr. 2003 & 1 & Plant and ratoon crop data; Foc \\
\hline
\end{tabular}

A Bits, sections of the rhizome.

${ }^{\mathrm{B}}$ Foc, plants were assessed for symptoms of fusarium wilt. 


\section{Results}

The $\mathrm{LD}_{50}$ for micropropagated Williams was about $30 \mathrm{~Gy}$ but shoot multiplication and general vigour of these plantlets was poor. The optimal dose was set at $20 \mathrm{~Gy}$ and used for mutation breeding trials. At this dosage, visual changes were apparent and plant survival, at $73 \%$, was sufficiently high to make the technique practical on a larger scale. The radiosensitivity of the Cavendish clones used in these experiments compares well with that found by Novak et al. (1990) for 'Grande Naine'.

Following irradiation of about 500 Dwarf Parfitt explants at a dose of $20 \mathrm{~Gy}, 35$ plants were observed in the field planting that possessed improved agronomic features. Plants were significantly taller than the extra-dwarf mother plants, they bunched earlier, their yield was greater and severe choking was eliminated (Smith et al. 1994). Bits of rhizome containing a growing point were removed from plants displaying no symptoms of fusarium wilt and were replanted in an adjacent Foc infested site, together with planting material from Williams and Dwarf Parfitt cultivars. Plant crop data of the $M_{1} V_{4}$ generation (i.e. the fourth vegetative cycle following 1 mutation induction treatment) revealed large differences in yield (Table 2) and assessments of micropropagated plants revealed differences in susceptibility to fusarium wilt between different mutant lines (Table 3).

There was a large group of mutant lines whose fruit bunch weight and finger length were comparable with those of Williams cultivars, as well as several lines with significantly poorer bunch weights and finger lengths. Dwarf Parfitt was significantly poorer, from an agronomic perspective, than all mutant lines selected. However, it had a very low incidence of fusarium wilt (an overall incidence of $8 \%$, consisting of 1 in 5 plants with external symptoms in August 1993 and 1 in 21 plants with internal symptoms in October 1997), whereas there was a great range of incidence of fusarium wilt in the mutant lines $(0-80 \%)$. Lines DPM2, 22, 25, 15 and 16 suggested fusarium wilt resistance was possible without a large loss in productivity and these, as well as several more resistant lines, were established as micropropagated plants for further tests and evaluation.

Evaluation of these more resistant lines grown on several more sites and during various seasons confirmed the

Table 2. Bunch weight and finger length of Williams, Dwarf Parfitt and putative mutants of Dwarf Parfitt at $M_{1} V_{4}$ generation following gamma irradiation

Cultivars and mutant lines were ranked according to mean bunch weight and finger length in the plant crop. Field trial was planted in November 1991 using bits (sections of rhizome) Means within each column followed by the same letter are not significantly different at $P=0.05$

\begin{tabular}{|c|c|c|c|c|c|}
\hline $\begin{array}{l}\text { Cultivar or } \\
\text { mutant line }\end{array}$ & $\begin{array}{l}\text { No. of } \\
\text { plants }\end{array}$ & $\begin{array}{c}\text { Bunch weight } \\
(\mathrm{kg})\end{array}$ & $\begin{array}{l}\text { Cultivar or } \\
\text { mutant line }\end{array}$ & $\begin{array}{l}\text { No. of } \\
\text { plants }\end{array}$ & $\begin{array}{c}\text { Finger length }{ }^{\mathrm{A}} \\
(\mathrm{cm})\end{array}$ \\
\hline DPM25 & 6 & $34.8 \mathrm{a}$ & Williams & 18 & $23.1 \mathrm{a}$ \\
\hline Williams & 18 & $33.5 \mathrm{a}$ & DPM22 & 6 & $23.0 \mathrm{ab}$ \\
\hline DPM2 & 7 & $32.8 \mathrm{ab}$ & DPM8 & 5 & $22.7 \mathrm{abcd}$ \\
\hline DPM5 & 9 & $32.5 \mathrm{ab}$ & DPM15 & 9 & $22.6 a b c$ \\
\hline DPM16 & 4 & 32.1 abcd & DPM2 & 7 & $22.4 \mathrm{abcde}$ \\
\hline DPM1 & 10 & $32.0 \mathrm{abc}$ & DPM16 & 4 & 22.1abcdef \\
\hline DPM19 & 6 & 31.5abcd & DPM18 & 7 & 22.1abcdef \\
\hline DPM15 & 9 & 31.3abcd & DPM13 & 8 & 21.9abcdef \\
\hline DPM12 & 7 & $30.7 \mathrm{abcd}$ & DPM11 & 9 & 21.8abcdef \\
\hline DPM27 & 11 & $30.5 \mathrm{abcd}$ & DPM19 & 6 & 21.8abcdef \\
\hline DPM13 & 8 & 30.0abcde & DPM27 & 11 & 21.6bcdef \\
\hline DPM24 & 8 & $29.2 \mathrm{bcde}$ & DPM24 & 8 & $21.6 \mathrm{bcdef}$ \\
\hline DPM11 & 9 & 29.1 bcde & DPM12 & 7 & $21.4 \mathrm{bcdefg}$ \\
\hline DPM3 & 12 & 28.6 bcde & DPM21 & 11 & $21.4 \mathrm{bcdefg}$ \\
\hline DPM22 & 6 & $28.6 \mathrm{bcdef}$ & DPM25 & 6 & $21.4 \mathrm{bcdefg}$ \\
\hline DPM18 & 7 & $28.6 \mathrm{bcdef}$ & DPM9 & 7 & $21.1 \mathrm{cdefg}$ \\
\hline DPM8 & 5 & $28.1 \mathrm{bcdefg}$ & DPM1 & 10 & $21.1 \mathrm{defg}$ \\
\hline DPM23 & 9 & $27.7 \mathrm{cdefg}$ & DPM4 & 14 & $20.9 \mathrm{efg}$ \\
\hline DPM4 & 14 & $27.2 \mathrm{defg}$ & DPM5 & 9 & $20.8 \mathrm{efg}$ \\
\hline DPM21 & 11 & $25.4 \mathrm{efg}$ & DPM10 & 8 & $20.7 \mathrm{fgh}$ \\
\hline DPM10 & 8 & $23.9 \mathrm{fgh}$ & DPM3 & 12 & $20.6 \mathrm{fg}$ \\
\hline DPM14 & 6 & $22.7 \mathrm{gh}$ & DPM23 & 9 & $19.9 \mathrm{gh}$ \\
\hline DPM9 & 7 & $20.0 \mathrm{~h}$ & DPM14 & 6 & $18.9 \mathrm{~h}$ \\
\hline Dwarf Parfitt & 5 & $\begin{array}{l}12.1 \mathrm{i} \\
\text { s.d. }=5.06\end{array}$ & Dwarf Parfitt & 5 & $\begin{array}{l}13.0 \mathrm{i} \\
\text { s.d. }=1.69\end{array}$ \\
\hline
\end{tabular}

AFinger length was measured from the middle finger of the outer whorl of the third hand from the proximal end. 
agronomic superiority of DPM25 compared with the other mutant lines (Table 4). Williams and DPM25 consistently had better yields and fruit size than other lines, whereas Dwarf Parfitt and DPM10 had consistently poor yields and fruit size. The majority of the DPM lines, including DPM2, DPM15, DPM16 and DPM22 also had a tendency to choke, whereas DPM25 did not. This is a condition when the bunch fails to emerge normally from the pseudostem and typically occurs when temperatures remain below $15^{\circ} \mathrm{C}$ for long periods in subtropical climates (Stover and Simmonds 1987). DPM25 also showed greater resistance to subtropical race 4 Foc than Williams (Table 3) and was therefore selected for further evaluation with Williams.

Bits were collected and a field trial established and maintained in a subtropical race 4 Foc infested block from 1998-2003. Bits were used owing to their greater resistance to Foc, compared with micropropagated plants (Smith et al. 1998), and were grown using commercial practices. A large number of traits were measured in both plant and ratoon crops of Williams and DPM25 and there were no significant differences in measured traits between Williams and DPM25 (Table 5). According to the agronomic traits studied, it was not possible to distinguish DPM25 from Williams in these trials.
During a period of high disease pressure prior to fusarium wilt assessments made in June 1993, there was a significant difference between Williams and DPM25 for severity and incidence of internal ratings of fusarium wilt $(P<0.05)$. However, when disease pressure was less severe, no significant differences were observed even though Williams had consistently worse infection and incidence of disease (Table 6). 'Bluggoe', a cultivar that is highly susceptible to subtropical race $4 F o c$, was significantly worse $(P<0.05)$ than these 2 cultivars for all comparisons made in April 2003 (internal and external for severity and incidence). Dwarf Parfitt, as expected, had a lower overall incidence of fusarium wilt than Williams and DPM25, and had significantly less internal symptoms $(P<0.05)$.

\section{Discussion}

Mutation breeding is a viable strategy for the improvement of bananas and plantains. The development of fusarium wilt resistant Cavendish bananas with acceptable yield and fruit quality is possible but has involved a considerable investment of time and resources as demonstrated by de Beer et al. (2001) and Hwang (2001). Their strategy was to develop subtropical race $4 F O c$ resistance in a commercially

Table 3. Incidence of fusarium wilt for Williams, Dwarf Parfitt and putative mutants of Dwarf Parfitt (obtained by gamma irradiation)

Cultivars and mutant lines were ranked according to the percentage of plants showing symptoms of fusarium wilt in the plant crop. The incidence of external fusarium wilt was assessed on August 1993 using plants established from bits (sections of rhizome) 21 months after planting. The incidence of internal fusarium wilt was assessed on October 1997 using micropropagated plants 11 months from planting

\begin{tabular}{|c|c|c|c|c|c|}
\hline \multicolumn{3}{|c|}{ Aug. 1993} & \multicolumn{3}{|c|}{ Oct. 1997} \\
\hline $\begin{array}{l}\text { Cultivar or } \\
\text { mutant line }\end{array}$ & $\begin{array}{l}\text { No. of } \\
\text { plants }\end{array}$ & $\begin{array}{c}\text { External incidence } \\
\text { of wilt }(\%)\end{array}$ & $\begin{array}{l}\text { Cultivar or } \\
\text { mutant line }\end{array}$ & $\begin{array}{l}\text { No. of } \\
\text { plants }\end{array}$ & $\begin{array}{c}\text { Internal incidence } \\
\text { of wilt }(\%)\end{array}$ \\
\hline DPM2 & 7 & 0 & Dwarf Parfitt & 21 & 5 \\
\hline DPM22 & 7 & 0 & DPM22 & 14 & 7 \\
\hline DPM10 & 9 & 11 & DPM16 & 20 & 10 \\
\hline DPM24 & 9 & 11 & DPM10 & 19 & 21 \\
\hline DPM19 & 9 & 11 & DPM2 & 13 & 23 \\
\hline DPM14 & 7 & 14 & DPM25 & 20 & 30 \\
\hline DPM3 & 13 & 15 & DPM18 & 17 & 35 \\
\hline DPM25 & 10 & 20 & DPM15 & 22 & 36 \\
\hline Dwarf Parfitt & 5 & 20 & Williams & 8 & 50 \\
\hline DPM16 & 5 & 20 & - & - & - \\
\hline DPM18 & 9 & 22 & - & - & - \\
\hline DPM13 & 8 & 25 & - & - & - \\
\hline DPM15 & 11 & 27 & - & - & - \\
\hline DPM27 & 11 & 27 & - & - & - \\
\hline DPM4 & 14 & 29 & - & - & - \\
\hline DPM9 & 10 & 30 & - & - & - \\
\hline Williams & 22 & 32 & - & - & - \\
\hline DPM1 & 12 & 33 & - & - & - \\
\hline DPM12 & 9 & 33 & - & - & - \\
\hline DPM23 & 10 & 40 & - & - & - \\
\hline DPM21 & 13 & 46 & - & - & - \\
\hline DPM5 & 11 & 55 & - & - & - \\
\hline DPM11 & 10 & 60 & - & - & - \\
\hline DPM8 & 5 & 80 & - & - & - \\
\hline
\end{tabular}


accepted cultivar. Our strategy also demonstrates that it is possible to start with an agronomically inferior but race 4 Foc resistant cultivar and select for lines with improved yield, productivity and fruit quality following mutation induction. However, both strategies involve trade-offs. In the program of Hwang (2001), it involved sacrificing improved agronomic characteristics for greater resistance to the pathogen. The results presented in this present paper have shown that mutant lines (e.g. DPM25) can be selected that are equal to the industry standard, Williams; however, the high degree of resistance to fusarium wilt shown by Dwarf Parfitt has been diminished in the process. Nevertheless, DPM25 has been shown to be significantly less affected by subtropical race 4 Foc than Williams and the incidence of infection has consistently been lower. Trials are currently underway in the Northern Territory to assess the reaction of DPM25 to tropical race 4 Foc , a far more devastating race of Foc.

Given that yield and fruit quality of Williams and DPM25 are similar, significantly improved productivity in soils infested with race 4 Foc is possible, as DPM25 has consistently shown a lower incidence of infection than Williams (Table 6). Even small improvements in resistance (e.g. a 5\% reduction in disease incidence) will ensure an overall higher yield per hectare. However, we believe a greater level of resistance is needed to obtain industry acceptance of this line. That DPM25 can be further improved is demonstrated by Tang and Hwang (1998) where recurrent mutation breeding and selection within the Tai Chiao No. 1 cultivar succeeded in decreasing incidence of infection from $11-20 \%$ to $3-12 \%$, and in significantly improving agronomic traits, such as plant height. Other strategies may

Table 4. Across years comparison of Williams, Dwarf Parfitt and putative mutants of Dwarf Parfitt (obtained by gamma irradiation)

Cultivar and mutant lines were ranked according to pseudostem height, bunch weight and finger length in the plant crop

\begin{tabular}{|c|c|c|c|}
\hline $\begin{array}{l}\text { Cultivar or } \\
\text { mutant line }\end{array}$ & $\begin{array}{c}\text { Plant crop }{ }^{\mathrm{A}} \\
\text { Nov. 1991-Nov.1993 }\end{array}$ & $\begin{array}{c}\text { Plant crop } \\
\text { Nov.1995-Oct.1998 }\end{array}$ & $\begin{array}{c}\text { Ratoon crop }{ }^{\mathrm{B}} \\
\text { Nov.1995-Oct.1998 }\end{array}$ \\
\hline \multicolumn{4}{|c|}{ Pseudostem height (m) } \\
\hline Williams & 2.92 & 2.28 & 2.53 \\
\hline DPM25 & 2.63 & 2.31 & 2.41 \\
\hline DPM16 & 2.88 & 1.79 & 1.79 \\
\hline DPM2 & 2.64 & 1.71 & 1.79 \\
\hline DPM22 & 2.45 & 1.68 & 1.81 \\
\hline DPM18 & 2.23 & 1.72 & 1.78 \\
\hline DPM15 & 2.39 & 1.67 & 1.72 \\
\hline DPM10 & 1.89 & 1.62 & 1.74 \\
\hline Dwarf Parfitt & 1.32 & 1.18 & 1.10 \\
\hline \multicolumn{4}{|c|}{ Bunch weight (kg) } \\
\hline Williams & 33.5 & 25.6 & 24.2 \\
\hline DPM25 & 34.8 & 24.2 & 23.3 \\
\hline DPM16 & 32.1 & 20.5 & 20.4 \\
\hline DPM2 & 32.8 & 20.2 & 20.4 \\
\hline DPM22 & 28.6 & 20.0 & 20.0 \\
\hline DPM15 & 31.3 & 20.8 & 18.6 \\
\hline DPM18 & 28.6 & 21.1 & 19.4 \\
\hline DPM10 & 23.9 & 14.8 & 15.9 \\
\hline Dwarf Parfitt & 12.1 & 9.0 & 6.5 \\
\hline \multicolumn{4}{|c|}{ Finger length ${ }^{\mathrm{C}}(\mathrm{cm})$} \\
\hline Williams & 23.1 & 20.9 & 21.5 \\
\hline DPM25 & 21.4 & 20.8 & 20.8 \\
\hline DPM15 & 22.6 & 20.2 & 19.8 \\
\hline DPM22 & 23.0 & 19.5 & 19.7 \\
\hline DPM2 & 22.4 & 18.9 & 19.7 \\
\hline DPM16 & 22.1 & 19.1 & 19.0 \\
\hline DPM18 & 22.1 & 19.1 & 19.0 \\
\hline DPM10 & 20.7 & 17.7 & 18.0 \\
\hline Dwarf Parfitt & 13.0 & 11.4 & 9.8 \\
\hline
\end{tabular}

A Field trial was planted using bits (sections of rhizome).

B Field trial was planted using micropropagated plants.

${ }^{C}$ Finger length was measured from the middle finger of the outer whorl of the third hand from the proximal end. 
need to be used to lower incidence of infection in Cavendish plantations, such as crop rotation practices that are known to reduce soil inocula levels (Moore et al. 2001).

The resistance of Dwarf Parfitt to race 4 Foc, compared with the susceptible Williams, was believed to have resulted from its greater retention of leaf area during winter, its higher chlorophyll concentration and more effective photosynthetic activity during winter (Moore et al. 1993; Pegg et al. 1996).
Because host defence reactions, such as the formation of gums, gels and tyloses used to block the invading pathogen, are presumably driven by photoassimilates, retention of the crop's high photosynthetic capabilities during winter was believed to effectively prevent widespread epidemics of fusarium wilt from occurring during spring and summer. In this present study, there was no difference in leaf number or leaf area between DPM25 and Williams at any stage

Table 5. A comparison of agronomic traits of Williams and DPM25 in a plant and ratoon crop

Values are means of 23-42 replicates. Field trial was established in October 1998 from bits. No significant differences between Williams and DPM25 were found for any measured parameter at $P=0.05$

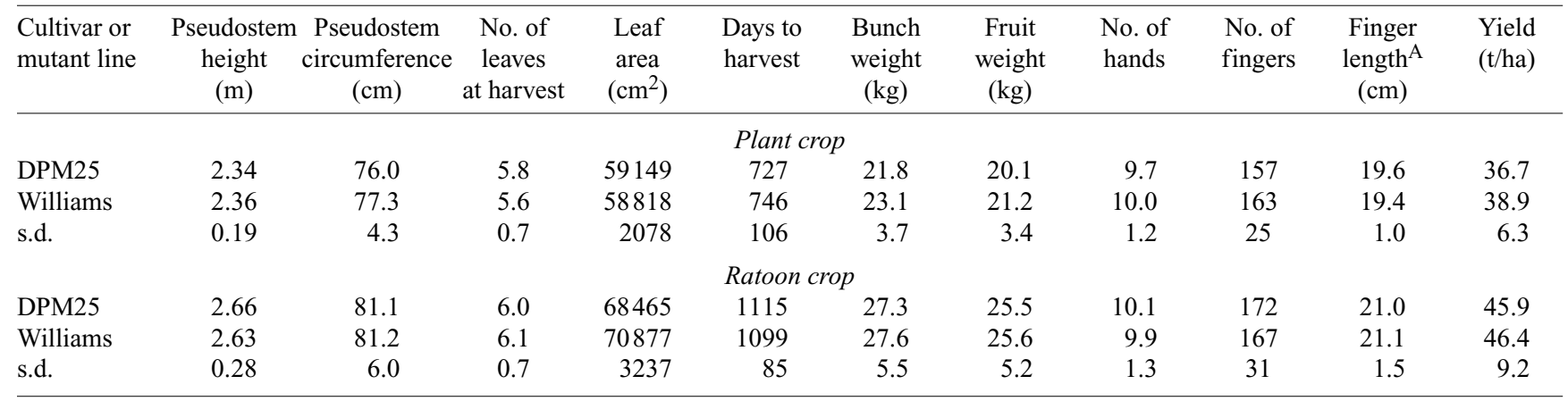

AFinger length was measured from the middle finger of the outer whorl of the third hand from the proximal end.

Table 6. Incidence and severity of fusarium wilt infection of Williams and DPM25, a Dwarf Parfitt mutant (obtained by gamma irradiation)

Micropropagated plants were assessed for external and internal symptoms of fusarium wilt 7-11 months from planting and plants established using bits (sections of rhizome) were assessed at harvest

Severity values given are average ranks and analysed using the Kruskal-Wallis test. Means for each assessment date within each column followed by the same letter are not significantly different at $P=0.05$

\begin{tabular}{|c|c|c|c|c|c|c|}
\hline Planting material & $\begin{array}{l}\text { Cultivar or } \\
\text { mutant line }\end{array}$ & $\begin{array}{l}\text { No. of } \\
\text { plants }\end{array}$ & $\begin{array}{l}\text { Foc external } \\
\text { infection }(\%)\end{array}$ & $\begin{array}{c}\text { Foc internal } \\
\text { infection }(\%)\end{array}$ & External rank $^{\mathrm{A}}$ & Internal rank ${ }^{\mathrm{B}}$ \\
\hline & & & June 1993 & & & \\
\hline \multirow[t]{3}{*}{ Micropropagated } & Williams & 12 & $67 \mathrm{a}$ & $100 \mathrm{a}$ & $14.8 \mathrm{a}$ & $16.2 \mathrm{a}$ \\
\hline & DPM25 & 13 & $38 \mathrm{a}$ & $69 \mathrm{~b}$ & $11.4 \mathrm{a}$ & $10.1 \mathrm{~b}$ \\
\hline & & & Aug. 1993 & & & \\
\hline \multirow[t]{4}{*}{ Bits } & Williams & 22 & $32 \mathrm{a}$ & - & - & - \\
\hline & DPM25 & 10 & $20 \mathrm{a}$ & - & - & - \\
\hline & Dwarf Parfitt & 5 & $20 \mathrm{a}$ & - & - & - \\
\hline & & & Oct. 1993 & & & \\
\hline \multirow{3}{*}{ Micropropagated } & Williams & 12 & $92 \mathrm{a}$ & - & - & - \\
\hline & DPM25 & 16 & $75 \mathrm{a}$ & - & - & - \\
\hline & & & Oct. 1997 & & & \\
\hline \multirow[t]{3}{*}{ Micropropagated } & Williams & 8 & - & $50 \mathrm{a}$ & - & $31.3 \mathrm{a}$ \\
\hline & DPM25 & 20 & - & $30 \mathrm{ab}$ & - & $27.0 \mathrm{a}$ \\
\hline & Dwarf Parfitt & 21 & - & $5 b$ & - & $20.7 b$ \\
\hline & & & Apr. 2003 & & & \\
\hline \multirow[t]{3}{*}{ Bits } & Williams & 31 & $3 a$ & $10 \mathrm{a}$ & $43.0 \mathrm{a}$ & $40.4 \mathrm{a}$ \\
\hline & DPM25 & 44 & $2 \mathrm{a}$ & $7 \mathrm{a}$ & $42.5 \mathrm{a}$ & $38.8 \mathrm{a}$ \\
\hline & Bluggoe & 15 & $40 \mathrm{~b}$ & $87 \mathrm{~b}$ & $59.5 b$ & $75.8 \mathrm{~b}$ \\
\hline
\end{tabular}

AExternal severity ratings on a scale of 1-3: 1, no symptoms; 3, severe symptoms.

${ }^{B}$ Internal severity ratings on a scale of 1-6: 1, no symptoms; 6, total vascular discolouration of rhizome (Jones 1994). 
(Table 5), although more work is needed to compare photoassimilation rates and relative cold tolerance between these plants.

This study has focussed on the role of mutation breeding for developing fusarium wilt resistant Cavendish cultivars; however, whether the putative mutants created were the result of somaclonal variation or physical mutagens is not known. Certainly gamma irradiation of meristems has been successfully used to develop a Cavendish line that flowers significantly earlier (Novak et al. 1990). It has been subsequently released as 'Novaria', and was entered into commercial production in Malaysia in 1993 (Mak et al. 1996). Somaclonal variation has also been exploited in micropropagated bananas and plantains with a range of desirable characteristics being uncovered (Smith et al. 2005). For instance, Daniells et al. (1999) noted a variant of 'Mons Mari' (AAA, Cavendish) with fruit $2-3 \mathrm{~cm}$ longer than usual for all hands and with the potential to boost profitability through increased sales of extra-large fruit. This clone has subsequently been released to industry as 'J.D. Special'. Until genetic transformation of Cavendish is routine and effective genes for fusarium resistance have been found and validated in field trials, future improvement in the Cavendish subgroup of dessert bananas will rely mainly on mutation breeding approaches.

\section{Acknowledgments}

We thank L. Pedwell for the use of his land as a race 4 Foc experimental site. The technical assistance of A. Hardwick and J. Hertrick is gratefully appreciated. Thanks also to J. Daniells for his constructive comments during his review of the manuscript. We acknowledge the financial support of the Australian Centre for International Agricultural Research, the Queensland Banana Industry Protection Board and Horticulture Australia Limited.

\section{References}

Becker DK, Dugdale B, Smith MK, Harding RM, Dale JL (2000) Genetic transformation of Cavendish banana (Musa spp. AAA group) cv. 'Grand Nain' via microprojectile bombardment. Plant Cell Reports 19, 229-234. doi:10.1007/s002990050004

de Beer ZC, Severn-Ellis A, Husselman JH (2001) Preliminary assessment of Cavendish banana clones for resistance/tolerance to Fusarium wilt. In 'Banana fusarium wilt management: towards sustainable cultivation'. (Eds AB Molina, NH Nik Masdek, KW Liew) pp. 194-200. (INIBAP: Montpellier)

Daniells JW, Reid DJ, Bryde NJ (1999) The banana selection J.D. Special has longer fruit and heavier bunches than cv. Williams but bunch losses are also increased. Australian Journal of Experimental Agriculture 39, 1013-1016. doi:10.1071/EA98183

Gall E, Vock N (1994) 'The Queensland banana industry kit.' South Queensland edn. (Queensland Government Printers: Brisbane)
Hamill SD, Smith MK, Dodd WA (1992) In vitro induction of banana autotetraploids by colchicine treatment of micropropagated diploids. Australian Journal of Botany 40, 887-896.

Hwang SC (2001) Recent development on Fusarium R\&D of banana in Taiwan. In 'Banana Fusarium wilt management: towards sustainable cultivation'. (Eds AB Molina, NH Nik Masdek, KW Liew) pp. 39-49. (INIBAP: Montpellier)

Jones DR (1994) 'The improvement and testing of Musa: a global partnership'. (INIBAP: Montpellier)

Mak C, Ho YW, Tan YP, Ibrahim R (1996) Novaria - a new banana mutant induced by gamma irradiation. InfoMusa 5, 35-36.

Moore NY, Pegg KG, Langdon PW, Smith MK, Whiley AW (1993) Current research on Fusarium wilt of banana in Australia. In 'International symposium on recent developments in banana cultivation technology'. (Eds RV Valmayor, SC Hwang, R Ploetz, SW Lee, NV Roa) pp. 270-284. (INIBAP/ASPNET: Laguna, Philippines)

Moore NY, Pegg KG, Bentley S, Smith LJ (2001) Fusarium wilt of banana: Global problems and perspectives. In 'Banana Fusarium wilt management: towards sustainable cultivation'. (Eds AB Molina, NH Nik Masdek, KW Liew) pp. 11-30. (INIBAP: Montpellier)

Murashige T, Skoog F (1962) A revised medium for rapid growth and bioassays with tobacco tissue cultures. Physiologia Plantarum 15, 473-497.

Novak FJ, Afza R, van Duren M, Omar MS (1990) Mutation induction by gamma irradiation of in vitro cultured shoot-tips of banana and plantain (Musa cvs.). Tropical Agriculture 67, 21-28.

O'Donnell JH, Sangster DF (1970) 'Principles of radiation chemistry.' (Arnold: London)

Pegg KG, Moore NY, Bentley S (1996) Fusarium wilt of banana in Australia: a review. Australian Journal of Agricultural Research 47, 637-650. doi:10.1071/AR9960637

Robinson JC (1996) 'Bananas and plantains.' (CAB International: Wallingford, UK)

Robinson JC, Nel DJ (1985) Comparative morphology, phenology and production potential of banana cultivars 'Dwarf Cavendish' and 'Williams' in the Eastern Transvaal Lowveld. Scientia Horticulturae 25, 149-161. doi:10.1016/0304-4238(85)90086-X

Smith MK, Hamill SD, Langdon PW, Pegg KG (1994) Mutation breeding for banana improvement in Australia. In 'The improvement and testing of Musa: a global partnership'. (Ed. DR Jones) pp. 233-242. (INIBAP: Montpellier)

Smith MK, Whiley AW, Searle C, Pegg KG, Langdon PW, et al. (1998) Micropropagated bananas are more susceptible to Fusarium wilt than plants grown from conventional material. Australian Journal of Agricultural Research 49, 1133-1139. doi:10.1071/A98013

Smith MK, Hamill SD, Becker DK, Dale JL (2005) Musa spp. banana and plantain. In 'Biotechnology of fruit and nut crops'. (Ed. RE Litz) pp. 366-392. (CAB International: Wallingford, UK)

Stover RH, Simmonds NW (1987) 'Bananas.' (Longman: Essex, UK)

Tang CY, Hwang SC (1998) Selection and asexual inheritance of a dwarf variant of Cavendish banana resistant to race 4 of Fusarium oxysporum f.sp. cubense. Australian Journal of Experimental Agriculture 38, 189-194. doi:10.1071/EA97110

Received 16 August 2004, accepted 23 December 2004 